\title{
Project Management Phases in Charity Based Organizations
}

\author{
Solaiman Al Mositeer \\ (Business Administration College, College/ Almajmaah university, Saudi Arabia)
}

\begin{abstract}
This paper shed light on project management practices in charities. The paper gives a roadmap for the practices conducted in such type of organizations starting from planning, to implementation and evaluation of the projects and the programs.
\end{abstract}

Keywords - Program Management, Project Management

\section{Introduction}

Project management will continue to be a highly desired skill in the midst of great change. Because rigid organizational boundaries and responsibilities have blurred and new technologies are changing the ways of doing business, results must be delivered more quickly and accurately than ever before. These circumstances call for people who can deal with ambiguity and time pressures while simultaneously accomplishing project goals - in other words, people who display excellence in project management.

In this paper, we present the route to achieving the scientific knowledge that will help to display excellence in PM in charity based organizations. This chapter also will present the basic principles, tools, and techniques so that readers can easily understand and apply the material.

\section{What is a Project?}

The PM Body of Knowledge define project as "a temporary endeavor undertaken to create a unique product, service or result"' (PMBOK, 2008, P.5).

The temporary nature of projects indicates a definite beginning and end the end is reached when the project's objectives have been achieved or when the project is terminated because its objectives will not or cannot be met, or when the need for the project no longer exists. Temporary does not necessarily mean short in duration. Temporary does not generally apply to the product, service, or result created by the project, most projects are undertaken to create a lasting outcome. The unique nature of projects indicates that every project creates a unique product, service, or result.. Although repetitive elements may be present at some project Deliverables, this repetition does not change the fundamental uniqueness of the project work (PMBOK, 2008, p.5).

\section{What is Project Management?}

Project management is the process of combining systems, techniques, and knowledge to complete a project within established goals of time, budget and scope (Macmillan, 2010, P10).

The PM Body of Knowledge defines project management as "the application of knowledge, skills, tools, and techniques to project activities to meet the project requirement s". PM is accomplished through the appropriate application of project (Initiating, Planning, Executing, Monitoring and controlling, and closing).

Cleland, Ireland define PM as " a series of activities embodied in a process of getting things done on a project by working with project team members and other stakeholders to attain project schedule, cost, and technical performance objectives." (Cleland, Ireland, 2002, P.39)

Table (1): The benefits of project management

\begin{tabular}{|l|l|}
\hline Past view & Present view \\
\hline PM will require more people and add the overhead costs. & $\begin{array}{l}\text { PM allows us to accomplish more work in less time with few } \\
\text { people. }\end{array}$ \\
\hline Profitability may decrease. & Profitability will increase. \\
\hline PM will increase the amount of scope changes. & PM will provide better control of the scope changes. \\
\hline $\begin{array}{l}\text { PM creates organizational instability and increases } \\
\text { conflicts. }\end{array}$ & $\begin{array}{l}\text { PM makes the organization more efficient and effective through } \\
\text { better organizational principles. }\end{array}$ \\
\hline Only large organizations need PM. & All kinds of organizations benefit from PM. \\
\hline PM will increase quality problems. & PM increases quality. \\
\hline $\begin{array}{l}\text { PM focuses on sub- optimization by looking only at the } \\
\text { project. }\end{array}$ & PM allows people to make good organizational decisions. \\
\hline The cost of PM makes the organization uncompetitive. & PM increases the value of the organization and delivers solutions. \\
\hline
\end{tabular}

Source: (kerzner, 2006, p.47) 


\section{What is Program Management?}

A program is defined as a group of related projects managed in a coordinated way to obtain benefits and control not available from managing them individually. Programs may include elements of related work outside the scope of the discrete projects in the program.

A project may or may be part of a program but a program will always have projects. Program management is defined as the centralized coordinated management of a program to achieve the program's strategic objectives and benefits .projects within a program are related through the common outcome or collective capability .if the relationship between projects is only that of a shared client, seller, technology, or resource, the effort should be managed as portfolio of projects rather than a program (PMBOK, 2008, p.9).

\section{2.5 Classical vs. Behavioral Approaches to Managing Projects}

The field of PM is currently in transition. What worked in the past may not necessarily work in the future, precisely because the world of business has changed. In the past, managing a project meant focusing on three key elements of a project: cost, schedule, and quality. Each element had a direct relationship with the other two. Do something to one and the other two would be affected, positively or negatively. This viewpoint is considered the classical approach for managing projects. The classical approach emphasized the formal, structural aspects. Managing projects meant building neat organizational charts and highly logical schedules, as well as using formal decision-making disciplines (Ludin and kelim, 1989, P.18).

Recently, however, PM has taken a more behavioral approach. The emphasis is shifting toward viewing a project as a total system, or subsystem operating within a system. This system perspective emphasizes the human aspects of a project as much as the structural ones. This does not mean that the formal tools, techniques, and principles are less important; it is just that they share the stage with behavioral techniques. The three elements - cost, schedule, and quality — gain an added dimension: people. Cost, schedule, quality, and people all play integral roles in the success or failure of a project. Indeed, it is quite evident that the behavioral aspects of a project can have an impact on final results. Individual and team motivations, informal power structures, and interpersonal communications can have as much an effect as a poorly defined schedule or an illdefined goal. In many cases, the impact of behavioral problems can be even more dramatic (Ludin and kelim, 1989, P.19).

The typical project cycle, as figure 1 shows, consists of four phases. During the Analysis phase, the idea of a project arises and preliminary cost and schedule estimates are developed at a high level to determine if the project not only is technically feasible but also will have a payback. In the Planning phase, the complete project plans are developed. These plans often include a statement of work, a work breakdown structure, and schedules.

The implementation phase is when the plan is executed. Energy is expended to achieve the goals and objectives of the project in the manner prescribed during the formulation phase. Then, in the installation phase, the final product is delivered to the customer. At this point, considerable training and administrative support are provided to "please the customer."

The Monitoring and evaluation phase covers the time the product, such as a computing system or a building, is under the customer's control and an infrastructure exists to maintain and enhance the product. Sometimes these phases occur linearly; other times, they overlap. (Ludin and kelim, 1989, P.25).

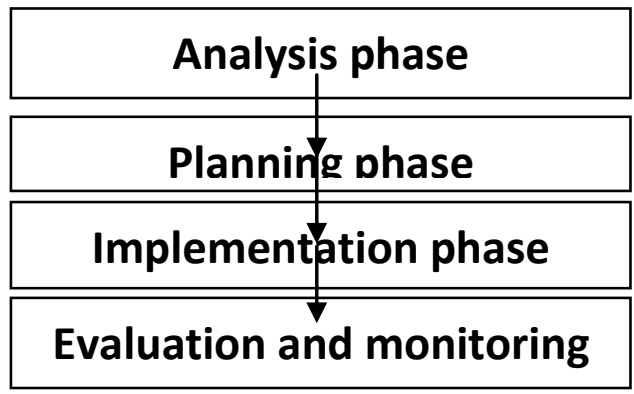

Source: (Ludin and kelim, 1989, P.25)

\section{The analysis phase}

Projects are designed to address the problems faced by beneficiaries, or by the site that is the target of the project, or (most commonly) both. A properly planned project addressing the real needs of the beneficiaries/site cannot be achieved without an analysis of the existing situation. However, the existing situation is likely to be perceived in different ways by different groups of stakeholders. Thus it is important to bring together representatives of all key stakeholders in the Analysis Phase. This is usually done in a workshop 
environment where problems and issues are discussed openly. There are four stages to the Analysis Phase: Stakeholders Analysis; Analysis of Objectives; Strategy Analysis and Problem Analysis (PMBOK, 2008, p.26).

\section{2.6.1.1 The problem analysis}

Problem analysis identifies the negative aspects of an existing situation and establishes the cause and effect' relationships between the problems that exist. It involves: Identification of the major problems and Development of a problem tree to establish causes and effects.

It is assumed that a need for an intervention exists if there is an undesired situation. The intervention (project) is meant to help solving the undesired situation. Within the LFA "undesired situation" is translated and crystallized into "problems". Analyzing problems therefore means to analyze an existing situation. During problem analysis the negative aspects of an existing situation are analyzed. Key problems are identified and the causal relationship between them. Initially information on the existing situation has to be collected and analyzed which, depending on the complexity of the circumstances, might take a long time. On this basis the stakeholders identified are consulted for their views and perceptions. The consultations can take place through various forms 21 that have to be chosen depending on the stakeholders. Often the consultations are organized as participatory workshops. "Brainstorming" can be used as a technique at the beginning of a workshop to identify key problems with the stakeholders. Having collected a number of key problems a so-called starter problem is selected to begin with clustering the problems and then creating a diagram of cause-effect relations (PMBOK, 2008, p.30).

\section{The objectives analysis}

While problem analysis presents the negative aspects of an existing situation, analysis of objectives describes a future situation that will be achieved by solving the problems identified. During analysis of objectives potential solutions for a given situation are identified. This involves the reformulation of the negative aspects ("problems") identified into positive ones (envisioned for the future) drawing up an "objectives tree" (Ludin and kelim, 1989, P.33).

In the objectives tree the objectives are structured in a hierarchical order and the former cause-effect relationships between the key problems are turned into means-end relationships between objectives (what needs to be done to achieve what?) (Ludin and kelim, 1989, P.33).

The objectives derived should reflect the future, desired situation but should be realistically achievable (which can be achieved by e.g. qualifying the objectives). The rationale of the reformulation is to derive the objectives directly from the actual existing problems identified and not from elsewhere. Looking at the former "starter problem" in the illustration case "untreated discharge of wastewater from households and factories into river is high" is now reformulated as an objective into "untreated discharge of wastewater from households and factories into river is reduced". By saying "reduced" the objective is qualified as the target will not be an absolute one ("no untreated discharge of wastewater from households and factories into river"). This absolute objective would, in this case, most probably be unrealistic. Qualifying the objectives at an early stage will also, later on, help to define targets (indicators).

As after having established the problem tree it is important to review the objectives tree (the meansend relationships) to ensure validity and completeness of the hierarchy of objectives. It might for example be necessary to revise statements or to add new objectives in case they seem to be relevant and necessary to achieve the objective at the next higher level (Ludin and kelim, 1989, P.34).

\section{The Stakeholder Analysis}

In order to maximize the social and institutional benefits of the project and minimize its negative impacts, it is extremely important to develop a comprehensive picture of the interest groups, individuals and institutions connected to the environmental problem and project idea.

Stakeholders and projects affect each other - in positive or negative ways. A project that does not take into account the views and needs of the various relevant stakeholders will hardly be able to achieve any objectives in a sustainable way. It is therefore crucial to start identifying and analyzing the relevant stakeholders, their interests, problems, potentials, etc. at an early stage to then integrate the stakeholders accordingly into the project design and management.

The procedure for stakeholder analysis is quite undetermined and open. Stakeholder analysis is methodologically not integrated into the LFA sequences will become evident later. The findings of the stakeholder analysis rather accompany the LFA process and can be pictured as a "transparency" that evolves throughout the early stages of the LFA project design process and should be used as an overlay to be in it for further elaboration or crosschecking during other LFA stages (Ludin and kelim, 1989, P.36). 


\section{The strategy analysis ("Analysis of Alternatives")}

The final stage of the analysis phase involves the identification of possible solutions that could form a project strategy and the selection of one or more strategies to be followed by the project. During strategy analysis (or "analysis of alternatives") a decision is being taken on which objectives will and which objectives won't be pursued within the frame of the project. The starting point for strategy analysis is the objectives tree. The choice of one or more strategies is made on the basis of criteria which have to be agreed upon and defined with the stakeholders, depending on the specific project context.

Possible criteria could be: costs, urgency, resources available, social acceptability, gender aspects, time perspective of benefits, feasibility, development policy guidelines, etc. The information gained during stakeholder analysis (potentials, support, resistance, etc.) and analysis of potentials should also be taken into consideration as a reference for decision taking. Having selected a project strategy the different levels of objectives (immediate objective and development goal) can be identified, which will later on be transposed into the logical framework matrix (or short form: log frame matrix) (Ludin and kelim, 1989, P.38).

\section{The Planning Phase}

The main output of the planning phase is the log-frame matrix. The log-frame sets out the intervention logic of the project (if activities are undertaken, then results will be achieved, then project purpose, etc.) and describes the important assumptions and risks that underlie this logic. This provides the basis for checking the feasibility of the project.

For management and supervision of projects, the log-frame defines the tasks to be undertaken, the resources required, and the responsibilities of management. In the second and third columns (objectively verifiable indicators, and sources of verification), the log-frame provides the framework against which progress will be monitored and evaluated (PMBOK, 2008, p.31).

\section{Logical Framework Approach}

A Logical Framework Approach (LFA) is a project design methodology that provides a systematic structure for identifying, planning and managing projects.

It was developed in the United States for USAID and has been adopted and adapted for use by other major donors including DFID and the EC. As experience has grown on what makes development aid more effective and accountable, an increasing demand for greater rigor in planning, implementing, monitoring and evaluating has led to the introduction of the LFA (Jensen, 2010, P.10).

The approach enables the main elements of a project to be concisely summarized and brings structure and logic to the relationship between project purpose and intended inputs, planned activities, and expected results. If used with flexibility this approach to planning encourages creative thinking and promotes participatory engagement between all parties throughout the project life-cycle (Jensen, 2010, P.10)

According to Jensen (2010, P.12), The LFA can help to achieve:

$>$ A structured project design process. LFA suggests a logical sequence, interlinking the individual steps in the design process.

> Transparency. The reasons why a certain project is meant to be implemented are laid open (what are the problems and whose problems are they?) as well as the internal logic of the project design (what is the project expected to achieve and how?).

$>$ Participation of the stakeholders involved in the project design and management, which is an essential prerequisite for the sustainability of a project.

$>$ Consistent project strategy. The LFA provides tools to clearly link causes and effects. To better assess risks it also takes into account external factors that are crucial for the success of the project, but lie outside the control of the project.

> Objectively verifiable indicators. Indicators describe objectives in measurable "empirically observable"14 terms and provide the basis for performance measurement and project monitoring and evaluation.

$>$ Flexibility in adapting to changing conditions (that are of relevance for the project). The LFA establishes a framework that makes the underlying rationales and assumptions transparent and helps to react to changes by, e.g., revising the design.

\section{Project Implementation phase}

Project implementation involves a number of activities. Among the major activities are securing community participation for launching the project, co-ordination of activities, monitoring, and taking care of contingencies. These activities are usually the responsibility of a project manager/ coordinator or a project management committee.

Of all these management activities three will be singled out: co-ordination, team-building and monitoring progress (Jensen, 2010, P26). 


\section{Evaluation and monitoring Phase}

Monitoring is a continuous internal process, conducted by managers, to check on de progress of project interventions against predetermined objectives and plans. Monitoring is an ongoing management task: have we achieved today what we set out to do? Where do we have to make adjustments in our plans? Regular reports on project implementation are the outcome of a monitoring process: was equipment available as planned, are activities on time (as mapped in the work plan), are the outputs produced on schedule? This kind of careful watching makes it possible to catch problems before they become unmanageable, and to take corrective action before it is too late. The reports can follow the log-frame and the work plan (Jensen, 2010, P. 50). In project and program management, evaluations usually have two objectives:

$>$ Lessons learning: to help all partners and stakeholders to learn from experience through discovering whether particular interventions have worked or not, and through understanding why they have been relatively successful or unsuccessful in particular contexts.

$>$ Accountability: to account for the use of financial resources to funders, such as the donor agencies themselves, the parliaments, taxpayers, foundations and individuals who provide their funds, and the beneficiaries in whose name the funds are raised and used (Jensen, 2010, P. 55).

\section{References}

[1] Jensen, G. (2010) "The Logical Frame Work Approach", 2nd. Edition, Bond Publishing

[2] Kerzner, Harold, (2006)."Project Management: A System Approach to Planning, Scheduling, and Controlling".

[3] Lanka, M. \& Martin, M. (2007). Strategically aligning your project portfolios: Introducing a new paradigm in project portfolio management. Paper presented at the annual North American meeting of the Project Management Institute, Atlanta, GA.

[4] Ludin \& Kelim.(1989) " Project Management Approach", 2nd. Edition, Basil Blackwell.

[5] Project Management Institute, "A Guide to the Project Management Body of Knowledge (PMBOK Guide)" Project Management Institute, Inc. (2008) 